\title{
ONTOLOGICAL AND EPISTEMOLOGICAL GROUNDING OF FUZZY THEORY
}

\author{
I. Burhan TÜRKŞEN \\ Director, Knowledge / Intelligence Systems Laboratory, Mechanical and Industrial \\ Engineering, University of Toronto, Toronto, Ontario, M5S 3G8, CANADA, \\ turksen@mie.utoronto.ca \\ http://www.mie.utoronto.ca/staff/profiles/turksen.html
}

\begin{abstract}
:
Ontological and epistemological grounding of fuzzy theory is discussed with a hierarchy of levels of theoretical inquiry and their questions. The hierarchy is of seven levels. At each level, we ask a fundamental question to expose one's standing with respect to acceptance or rejection of the positions. At the bottom there are the two ontological questions; next there are the two general epistemological questions; then there are the two domain specific epistemological questions; and finally there is the application level questions. The hierarchy is shown to elicit the crisp (classical) set and logic theory stance and the fuzzy set and logic stances. We discuss only the first six levels in this exposition.
\end{abstract}

Özet:

\section{Bulanık Mantık Teorisinin Ontolojik ve Epistomolojik Temelleri}

Bulanık Mantık Teorisinin, ontolojik, epistemolojik temelleri teorik sorgulama seviyeleri hiyararşisinde tartışılmıştır. Hiyerarşi yedi seviyeden oluşmaktadır. Her seviyede bir temel soru sorulmuştur. En altta iki ontolojik soru mevcuttur; sonraki seviyede iki genel epistemolojik soru; daha sonrakinde iki alan-özgü epistemolojik soru ve son olarak da uygulama seviyesi soruları vardır. Hiyerarşi, klasik küme ve mantık teorisi ile bulanık küme ve mantık duruşunu açığa çıkaracak şekilde verilmiştir. Bu çalışmada yalnızca ilk altı seviye tartışılmıştır.

Keywords: Ontology, epistemology, grounding, fuzzy, sets, logics, hierarchy. Anahtar Sözcükler: Ontoloji, epistemoloji, bulanık küme, bulanık mantık, hiyerarşi. 


\section{INTRODUCTION}

As fuzzy theorists and practitioners, we frequently find ourself confronting significant philosophical issues in our work. Indeed, if we are not doing so, we are probably and possibly missing out a lot. While different fuzzy theories and application approaches may be founded upon different set of philosophical presuppositions, all such theories rest upon some epistemological and ontological assumptions, whether explicitly acknowledged or not.

As well, at times, this creates a situation of discord, or at least a level of misunderstanding, between fuzzy theorists and practitioners on the one hand and the crisp theorists and practitioners on the other. In fact, lack of clearly communicating our philosophical stance have caused and still causes a lack of understanding and/or rejection of fuzzy theory by those who held on to the classical view of the world. Furthermore, it does not help us to explain effectively to managers and decision makers, how fuzzy theory and fuzzy system models could improve their decision-making practices. Some decisionmakers are still hesitant to embrace the fuzzy system models, despite the fact that significant and important applications of fuzzy theory are implemented and installed in many electro-mechanical systems, e.g., robotics, camcorders, washing machines, train break-systems, auto-transmission systems, unmanned helicopter control and navigation, etc., etc.

The problem is that more often than not the underlying philosophical assumptions are overlooked or not dealt with in a sufficiently conscious, explicit, detailed, and reflective manner. Frequently, they are left at a vague, imprecise, i.e., unprecisiated, and implicit level, and occasionally they are disavowed outright as in the atheoretical stance. Yet these hidden assumptions continue to exert a highly significant influence upon the ways in which the researchers and practitioners understandings of a particular case study or a system model, will be framed, organized, or subtly structured.

At times, it seems as if we in the fuzzy disciplines have been waiting for philosophers or someone else to come along and help us to make our philosophical unconscious more conscious, while we have played the role of a very cooperative participant in the development of the theory and/or its applications.

It is well known that Lotfi A. Zadeh has provided a continuous stream of novel and seminal ideas, from fuzzy sets, to fuzzy logic, to approximate reasoning to syllogistic reasoning, to computing with words and computing with perceptions. In this regard, we are greatly indebted to him for his continuing leadership. But very few of us have taken up some of his suggestions and 
clearly stated our particular stance in a systematic and constructive manner. I do not mean to state that we have not done significant progress over the last thirty six years or so. We have, but we still have to do a lot more.

Many researchers and practitioners have contributed to the theory and its applications in their specific area of concern. At times some have stated their particular assumptions. But a unified view of the theory has not been stated in explicit philosophical content.

Part of the problem has been methodological. Despite the many significant developments, there have been few systematic or comprehensive attempts made to look at the complex and interweaving relationship among the philosophical and scientific issues in question. In this paper, we present a methodology with which one might explore the important philosophical bases of our fuzzy theories in a more structured and perhaps a more rigorous manner. In particular, we articulate ontological and epistemological stances.

In applications, philosophical positions are taken up more or less simultaneously on several different levels of theoretical inquiry. However, we do not deal with these issues in this paper.

It is thus important for us to be able to ascertain that our positions on these different levels of inquiry are consistent with one and other. That is, we must demonstrate that our theories have some overall coherence to them. The method presented in this paper is particularly suited to provide such demonstrations for ontological and epistemological concerns at times implicit and at other times explicit.

\subsection{Underlying Philosophical Bases}

An overview of a systematic approach to reviewing and observing philosophical issues of fundamental importance to the classical paper and fuzzy theories is presented below. This method involves an analysis of the stated or implied stances taken by any given fuzzy theory on a structured series of essential philosophical questions.

A hierarchy of levels of theoretical inquiry has been developed, and proposed which includes the Ontological, the Epistemological, and Domain Specific Epistemological, Levels. Each level of this hierarchy poses its own fundamental philosophical questions. Each of these levels and questions in turn provides the philosophical "grounding" of subsequent ones. A given classical or fuzzy theory, and the many of the philosophical pre-suppositions inherent to it, may then be illustrated and classified by exploring the set of propositions 
adopted by it on this series of crucial questions. The results of these inquiries may then be summarized hierarchically as will be demonstrated.

\subsection{Hierarchy of Levels of Theoretical Inquiry}

A hierarchy of levels of theoretical inquiry and their questions, which are thought to be pertinent and essential, are being examined and which have been used as the framework for this approach is depicted in Table 1.

The bottom level in this hierarchy are foundational to others: positions from Level $\mathrm{i}$ form the "grounding" or the conditions for the possibilities of positions on Level ii; those of ii ground iii; etc, The Table is read from bottom level up: from $\mathrm{i}$ to vi. Thus, on the application level vii, insights and theories are seen to rest upon a series of positions taken on each of the supporting levels $\mathrm{i}$ through vi.

\subsubsection{Level i}

At the bottom, theoreticians of any sort must address the most fundamental of philosophical questions:

"Is there any such thing as fuzziness independent or partially independent of us?" As well, "are there fuzzy sets" or "are there any absolute crisp sets" as well as "Is there fuzzy truth?" or, "Is there any absolute truth?" These questions about the existence of Reality as such are on what I refer to as the Ontological Level of Inquiry. It seems obvious that whether one answers yes or no to these questions will have profound implications for all other levels of the theory. Type of theories and science that we propose and construct in fact depend on whether we answer "yes" or "no" to these questions. Indeed, if one answers "yes" to the first question and "no" to the second question, it is arguable that classical theories and science has to be re-assessed and must be rendered relevant on a new grounding. As such, this level is considered most fundamental or foundational. It is well known that Classical set and logic theorist's stance is "yes" that there is "the absolute Truth" and "yes" to crisp sets and that there is a crisply defined Reality that exists independent of us. Whereas the stance that fuzzy theorist take is that there is no absolute truth and there is no crisp sets and that there is a fuzzily defined Reality beginning with Zadeh's seminal paper (1965), i.e., that the "Truth" is a matter of degree and set membership is graded and that the Reality is dependent on our perceptions (Zadeh, 1999). 


\subsubsection{Level ii}

Still within the realm of ontology, a further, higher-level question then arises: "What is our position or relation to that Reality"? Are we originally separated or apart from it, or is it the very essence of our being relational in this respect? Some philosophical and scientific traditions take up stances very different from others on this still quite a fundamental level.

The classical view is that our relational being to Reality is all or none. That is the elements of reality and their belonging to a set is "all or none". As well as the relation of these elements between sets is "all or none". The fuzzy view is that our relational being to reality is a matter of degree. That is the elements of reality in their belonging to a set as well as in their relation to each other between sets is a matter of degree, i.e., there are partial memberships in a set and partial degrees in participating in relation between sets. And the degrees of truth of these membership values are also partial. This is compatible and in agreement with the level i stance that partial membership, partial participation in relations and partial truth are all perception based and expressed in our use of words and thus computing with words.

\subsubsection{Level iii}

Next level above the Ontological level is the General Epistemological Level of inquiry. The questions of general epistemology ask, "What is our access to truth or knowledge?", "Where is truth found in our paradigm?", "How are the membership values acquired?", "How or from what is it constituted?" These questions are addressed on this level in order to deal with the nature of human knowing in general. That is once we take a stance on "Truth" or "membership" being absolute or partial, then we have to explicitly state how we obtain them.

\subsubsection{Level iv}

Based upon the stances adopted on Level 3 and still within the realm of epistemology will be questions of General Validity: "Given our General epistemological position on Level iii, "How do we validate our knowledge? How do we know it is true? What criteria do we use to assess its truth-value?" Again these questions are asked from the standpoint of the position and limits on human being or human knowledge in general. 


\subsubsection{Level v}

The next major level of inquiry in the hierarchy is the Domain Specific or Discipline-Specific Epistemological Level. At this level, our questions take the form not of what human beings can know in general; but rather given our general epistemological and ontological position taken below on level iv, the more specific question is "What can we know or hope to know or learn, within discipline or setting (e.g., what can we know from within the experimental setting in terms of sampled training and testing data sets)?" Assertions on this level may include domain specific field experiments delimiting our statements, or positions (proposition) that attempt to define the proper limits or "horizons" to a given domain specific field.

\subsubsection{Level vi}

As was the case with the General Epistemological Level, the DomainSpecific Epistemological Level positions will also provide a basis for domain specific theories of validity, and thus of appropriate methodologies as well.

\subsubsection{Level vii}

Finally, it is only after implicitly or explicitly addressing all previous levels that we come to the Application Level of Inquiry proper. It is at this level of inquiry that our questions about system analysts and designers, managers, decision-makers, doctors, lawyers, engineers, etc. etc., feel, behave, think, and interact, are raised, and our insights, theories, and different emphases are debated in our attempts to better understand them and support them. However, this level requires a rather length discussion on "decision making" and systems theories in particular in the light of uncertainty and imprecision. Thus, we intent to investigate these in a separate paper. 
Table 1. Hierarchy of Levels of Theoretical Inquiry And Their Questions

APPLICATION LEVEL

vii. How do people, decision-makers, feel, think, behave, and interact?

How can we provide them with better decision-making tools?

DOMAIN-SPECIFIC EPISTEMOLOGICAL LEVEL

vi. How do we validate knowledge appropriately in this domain specific field? What methodological approaches are appropriate to it?

v. What can we know or hope to learn within this domain-specific field or discipline? What are the limits or boundaries to it?

GENERAL EPISTEMOLOGICAL LEVEL

iv. How do we validate our knowledge? How do we know it is true? What criteria do we use to assess its truth-value?

iii. What is our access to truth or knowledge in general? Where is truth to be found? How or from what is it constituted?

ONTOLOGICAL LEVEL

ii. What is our position or relation to that Reality (if we do assume that it exists on level 1 below)?

i. Is there any reality independent or partially independent of us? Does any absolute truth exist?

Does fuzziness exists?

Naturally, one might additionally propose various sub-levels within this complex hierarchy suggested in Table 1. But for the purpose of this paper, the key point is that at the Application Level vii issues should not be tackled in isolation from their philosophical underpinnings. For as important as the theoretical, pragmatic and methodological controversies and different emphases that are within this level, changes of position that occur at lower levels of the hierarchy may even more profoundly shake the foundation of all that rest upon them. Such changes may be similar to a theoretical earthquake, which necessitates a great deal of subsequent rebuilding. In fact the introduction of the fuzzy set (Zadeh, 1965) has caused such a revolutionary (Grand) paradigm-shift (Khun, 1962) which resulted in subsequent rebuilding of fuzzy theory, approximate reasoning and computing with words. 


\section{CLASSICAL VS FUZZY THEORY}

Classical set and logic theory, at times known as Aristotelian theory, in contrast to Fuzzy set and logic theory, at times know as Zadehian theory, will be sketched out and articulated below in terms of the philosophical hierarchy discussed in the previous section. The purpose of this sketch at this juncture is primarily methodological; that is, it is presented more as a demonstration of the sort of analysis that may be facilitated by the hierarchical method described above in Section 1.

\subsection{A Hierarchical Sketch of the Classical Set and Logic Theory Model}

Classical theory is a well known reductionist theory that has helped us over more than two thousand years with many applications in explanations of physical and natural phenomena and electro-mechanical men made devices. In Table 2, we now give a sketch of classical theory.

Table 2. Positions Taken by Classical Set and Logic Theorists on the Hierarchy of Levels of Theoretical Inquiry

\begin{tabular}{ll}
\hline \hline $\begin{array}{l}\text { Application } \\
\text { Level }\end{array}$ & $\begin{array}{l}\text { vii. Emphasis on mechanistic Super additive systems } \\
\text { theory of interactions, relations, equations, etc. }\end{array}$ \\
$\begin{array}{l}\text { Eomain Specific } \\
\text { Level }\end{array}$ & $\begin{array}{l}\text { vi. Validity and methodology dictated by } \\
\text { meta-physical theories. e.g., principle of determinism } \\
\text { and randomness. } \\
\text { v. Objective facts and truth accessible, but limited } \\
\text { only by subjective distortions. }\end{array}$ \\
& $\begin{array}{l}\text { iv. Correspondence theory of Validity } \\
\text { only accessibly by Objective methods }\end{array}$ \\
$\begin{array}{l}\text { iii. Objectivist, empiricists } \\
\text { Epistemological }\end{array}$ & $\begin{array}{l}\text { ii. sRo Cartesian dualism } \\
\text { i. Realism, crisp }\end{array}$ \\
$\begin{array}{l}\text { Ontological } \\
\text { Level }\end{array}$ & \\
\hline
\end{tabular}

On the Ontological Level, Level i, of the proposed hierarchy, we must believe firmly in an observer-independent absolute reality. The classical theory subscribes to the Cartesian "sRo" paradigm of describing our primary relation to that Reality on level ii. By the sRo paradigm, we refer to that ontological model 
that posits the subject, s, and the object (or world), o, as initially (at least in principle) separate from each other but subsequently connected by some sort of relational, $\mathrm{R}$, event. The prototypical relational event of this sort has been seen as that of the primary cognitive act of "knowing"; i.e., subject and object come to be related through the subject's coming to know the object. The Cartesian split, between the subject and the object as well as between the mind and the body, appear to have been embraced by Classical thinkers throughout most of their theorizing. Such dualistic dichotomous thinking is well recognized and accepted by the defenders of the classical theory. Without reiterating all of their arguments here, Cartesian dualism, or sRo ontological model, inherit much of the terminology of the two-valued set and logic theory with its well known axioms that are exhibited in Table 3.

Table 3. Axioms of Classical \& Set \& Logic Theory

\begin{tabular}{|l|l|}
\hline Involution & $\mathrm{c}(\mathrm{c}(\mathrm{A}))=\mathrm{A}$ \\
Commutativity & $\mathrm{A} \cup \mathrm{B}=\mathrm{B} \cup \mathrm{A}$ \\
$\mathrm{A} \cap \mathrm{B}=\mathrm{B} \cap \mathrm{A}$
\end{tabular}

Briefly, every element belongs to a concept class, say A, either with full membership or none, i.e.,

$\mu_{\mathrm{A}}: X \rightarrow\{0,1\}, \mu_{\mathrm{A}}(\mathrm{x})=\mathrm{a} \in\{0,1\}, \mathrm{x} \in \mathrm{X}$, where $\mu_{\mathrm{A}}(\mathrm{x})$ is the membership assignment of an element $\mathrm{X} \in \mathrm{X}$ to a concept class $\mathrm{A}$ in a proposition.

Furthermore, this descriptive assignment, $\mathrm{D}_{\{0,1\}}$, is verified or asserted to be absolutely True, $\mathrm{T}$, or False, F, i.e., $\mu_{\mathrm{V}}: \mu_{\mathrm{A}} \rightarrow\{\mathrm{T}, \mathrm{F}\}$, where $\mathrm{V}_{\{\mathrm{T}, \mathrm{F}\}}$, is the veristic assignment which is the atomic building block of two-valued logic. 
On the Ontological Level, Levels $\mathrm{i}$ and ii the acceptance of the descriptive assignment $\mathrm{D}_{\{0,1\}}$ and the Veristic assignment, $\mathrm{V}_{\{0,1\}}$ provide us the grounding for the formation of Two-valued "Truth Tables" and in turn for the derivation of the combination of concepts for any two crisp sets $A$ and $B$ to be

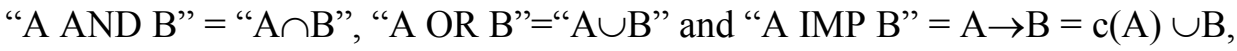
etc. This means that linguistic connectives "AND", "OR", "IMP", etc., are interpreted in a one-to-one correspondence, isomorphically to be equal to " $\cap$ ", " $\cup ", \mathrm{c}(.) \cup "$ ".

That is the imprecise and varying meanings of linguistic connectives are precisitated in an absolute manner analogous to the absolute precisiation of the meaning of words in terms of absolute crisp set representation. And all this is done for the sake of developing a "reductionist" theory of knowledge representation and reasoning with it!

On the General Epistemological Level iii, we have the foundation of the objectivism. Its stance is that real truth exists, potentially accessible, and are to be found on the object side of the Cartesian split. The "subjective" elements, although understandable or symbolically meaningful, and of immense scientific interest, were nevertheless seen as basically unwanted distortions to be removed or eliminated (as much as possible) in order to get at the obscured "objective crisp set membership and truth".

On this General Epistemological Level, first at level iii, the observation based data are to be obtained from objects with the use of measurement agents such as sensors that are precise. Thus representations of objects are developed on measurement based data warehouses. This is done with the assumption of the fact that measurement based models so developed are to stand on the foundation developed on the Ontological level. They are consequently descriptive representations of model concepts that stand on two-valued set theory, i.e., $\mathrm{D}_{\{0,1\}}$ which are verified with the two-valued logic theory, $\mathrm{V}_{\{0,1\}}$.

Not surprisingly, on level iv of the proposed hierarchy, dealing with General Theories of Validity, a "correspondence theory of truth" is accepted in most classical scientific investigations. According to this theory, a perception, or an observation, or a judgment is considered valid or true insofar as it may be shown to match exactly with the objective or factual reality of the world around us.

Hence on level iv, the "correspondence theory of truth" essentially is based on the two-valued set and truth framework, i.e., Description and Verification, $\mathrm{D}_{\{0,1\}}, \mathrm{V}_{\{0,1\}}$, which are accepted on the Ontological level. This 
means that models developed on the General Epistemological level are to be accepted as true depictions of real system behaviour. Furthermore, test data are to be used to validate results obtained from the model build on the level iii. Thus results are assumed to computationally determine as acceptable outcomes for given inputs of the test data.

Therefore on the General Epistemological level, we first have a model expressed in a general form as " $\mathrm{A} \rightarrow \mathrm{B}$ " as a descriptive model $\mathrm{D}_{\{0,1\}}$ which is verified as $\mathrm{V}_{\{0,1\}}$ within the frame work of a classical inference schema such as Modus Ponens which is stated as $(\mathrm{A} \rightarrow \mathrm{B}) \mathrm{A}=\mathrm{B}$ such that the premise, $\left\{\mathrm{D}_{\{0,1\}}\right.$, $\left.\mathrm{V}_{\{0,1\}}\right\}$ for " $\mathrm{A} \rightarrow \mathrm{B}$ ", combined with the premise $\left\{\mathrm{D}_{\{0,1\}}, \mathrm{V}_{\{0,1\}}\right\}$ for " $\mathrm{A}$ " results in a consequence which exactly matches the right hand side of the crisp rule, i.e., $\mathrm{B}$, described and verified as $\left\{\mathrm{D}_{\{0,1\}}, \mathrm{V}_{\{0,1\}}\right\}$, provided that the observation $\mathrm{A}$ matches exactly to the left hand side of the rule. The validation is based on a comparison of the actual output for a given test input data and model output for the same test input data. The error is usually accepted to be a true, $\mathrm{V}_{\{0,1\}}$, verification based on a statistical risk which is to be a crisply evaluated assessment dependent on a crisply test of hypothesis.

On the Domain-Specific Epistemological level, the classical system development models that stand on observations which are measurement based data stored in data warehouses for a specific field of inquiry. Measurement data that is suppose to capture the system behaviour and its associated concepts that are represented with linguistic variables and linguistic terms are expressed in two-valued descriptive set theory $\mathrm{D}_{\{0,1\}}$. Therefore system models so developed are assumed to be universally valid representations of domain specific object world that is captured by measurement based data only! That is, they are verified to be absolutely true, i.e., $\mathrm{V}_{\{0,1\}}$. It is assumed that they are precise.

On level $\mathrm{v}$ of the hierarchy, dealing with the Domain-Specific Epistemology, for a particular investigation, the scientists appear to find limits to knowledge only on the subjective side of the Cartesian split. It is assumed that such subjective distortions may originate in the (system) analyst, but the "untruths" are all seen as coming from the s-or subject- side of the sRo split. The scientists seem to see few or no limits on the object side, That is, the object seems to be just what it is factually; it is not ambiguous, or imprecise in itself, only in our misperceptions of it or in our measurement errors of it.

It is interesting, to note, however, in the case of the Domain-Specific Epistemology endorsed by classical thinking, such "objective facts of the world" (which by definition stand as true, regardless of our will, mood, or perspective on them) may include both external states in the world as well as 
certain "internal" (though nevertheless still "objective"), be abstract, states or realities. Classical science, seen from the epistemological view-point, appears to have just discovered the internal abstract states, as it were, out there in the world. That is Classical science, in this perspective, does not accept that they have been created as concepts and have been expressed linguistically by subjects. Such internal, abstract, concepts are then considered to be universally valid features of the objective world. That is linguistic variables and their terms are assumed to have crisp well defined meanings.

In terms of Level vi of the proposed hierarchy, science deals with the question of validity and methodology in the domain specific field of study with reductionism and commitments to specific cause and effect hypothesis and metaphysical theories, e.g., drive a theory and investigate its derivatives. At times, this tended to arbitrarily restrict what was to be considered valid data and not within the particular domain of interest. For example, a good scientist of this persuasion should be actively searching for "derived derivatives" and attempt to find their origin in more primary theoretical precepts in accordance with the classical model.

On the Domain-Specific Epistemological Level, we find various developments of system models with application technologies known as statistical methods, such as multi-variate regression equation, programming methods such as linear and non-linear optimization algorithms or optimal control schemas developed on objective data that are obtained by measurement devises and depend on description and validation frameworks that are given as $\left\{\mathrm{D}_{\{0,1\}}, \mathrm{V}_{\{0,1\}}\right\}$.

As well the validation of the Domain-Specific models are assessed with domain-specific test data that are assumed to be standing on descriptive and verified framework of $\left\{\mathrm{D}_{\{0,1\}}, \mathrm{V}_{\{0,1\}}\right\}$. The validations of the domain specific models are executed with the classical inference schemas such as Modus Ponen as indicated above.

This may entail a re-computation of, say, regression, or programming or control models with test data. Results obtained from such models are assumed to be on $\left\{\mathrm{D}_{\{0,1\}}, \mathrm{V}_{\{0,1\}}\right\}$ framework based on some level of crisp risk.

This approach, however, may be seen by many to be quite problematic in that the theories and methods most properly belonging to the Application Level vii appear here to be dictating what qualifies as good and valid data on the Domain Specific Epistemological Level vi. Such situation in which the positions on lower levels of the hierarch are overtly dictated by higher ones is generally not recommended in this hierarchical approach. For the more the 
Application Level vii theory determines or dictates what to be considered as valid knowledge in the field, the less likely it will be that anything not in conformance with the theory will ever be found, noticed, or admitted as evidence. This in fact was the case for the rejection of fuzzy theory by orthodox, doctrinaire defenders of the classical theory. While such a hegemony of the Application Level vii theory may appear to increase the coherence by guaranteeing a certain amount of conformity, it will also provide a basis for the systematic neglect of other potentially valid but contradictory observations such as the existence of gray between the black and white dichotomy.

\subsection{A Hierarchical Sketch of Fuzzy Set and two-valued Logic Theory Model}

Indeed several critical thinkers of the classical theory have argued that it restricts or reduces reality to be "objective"; and that classical theory leads inadvertently to many paradoxes in which the theory becomes over-structured, over-selective, and sometimes even overshadows the real life data, e.g., Russle's paradox, Barber's paradox, Flackross paradox, etc, etc. Such paradoxes ought to be demonstrations for the importance of our being as conscious and aware as we can be of the philosophical presuppositions embodied in our application theories.

This is particularly so with respect to real-life experimental data, and thus the call of fuzzy theorists for more "experience-near" concepts and "expertinsight" approaches for the formation of fuzzy-expert system models. These models are either formed by expert interview or by fuzzy data mining exercises more generally a combination of both.

The fuzzy theory is a non-reductionist theory that captures the gray information granules between black and white. Furthermore, it helps us to cope with the complexity of our modern world in decision-making processes in a manner akin to human decision-making.

In this theory, the paradoxes of two-valued classical theory are explained by the admission of the gray information granules between black and white and hence allowing overlaps between classes and categories.

In Table 4, we next give a sketch of the fuzzy theory in terms of the proposed hierarchy as we interpret them. 
Table 4. Position Taken by some Theorists of Fuzzy Set and Logic Theory on the Hierarchy of Levels of Theoretical Inquiry

\begin{tabular}{ll}
\hline \hline $\begin{array}{l}\text { Application } \\
\text { Level }\end{array}$ & $\begin{array}{l}\text { vii. Emphasis on humanistic non-linear systems theory of } \\
\text { overlaps with fuzzy interactions, relations, equation, rules, etc. }\end{array}$ \\
$\begin{array}{l}\text { Domain Specific } \\
\text { Epistemological }\end{array}$ & $\begin{array}{l}\text { vi. Validity and methodology dictated by meta-linguistic } \\
\text { theories of imprecision and uncertainty. } \\
\text { v. Subjective perception based facts and truth are accessible } \\
\text { to capture imprecision and uncertainty. }\end{array}$ \\
& $\begin{array}{l}\text { iv. Correspondence theory of Validity with an integrated } \\
\text { perspective objective and subjective views, }\end{array}$ \\
$\begin{array}{l}\text { General } \\
\text { iii. Subbjectivist "experience-near", "expert-insight" } \\
\text { Level }\end{array}$ & $\begin{array}{l}\text { ii. sR } \text { oR }_{2} \text { s humanistic realism. } \\
\text { i. Realism, imprecise and approximate defined by a continuous } \\
\text { membership. }\end{array}$ \\
Level &
\end{tabular}

On the ontological level, level i, of the proposed hierarchy, we must believe firmly in an observer-dependent and relative reality that is perception based and communicated and computed with words and their numeric meaning representation with continuous memberships.

On level ii, the classical sRo Cartesian dualism is modified and extended to be " $\mathrm{sR}_{1} \mathrm{O} \mathrm{R}_{2} \mathrm{~s}$ " paradigm that describes a subject's primary relation to an object to be $R_{1}$ and in turn a object's relation to a subject to be $R_{2}$. By the "s $\mathrm{R}_{1} \mathrm{oR} \mathrm{R}_{2} \mathrm{~s}$ " paradigm, we refer to an ontological model that posits subject, $\mathrm{s}$, and object, $\mathrm{o}$, to be inter connected with relations $R_{1}$ and $R_{2}$.

The prototypical relation $\mathrm{R}_{1}$ is interpreted as the primary cognitive act of "knowing" based on perception of subjects and articulated in a natural language, i.e., Computing With Words, CWW, followed by objects', o's, meaning representation in terms of continuous membership values that are next processed by relation $R_{2}$ that generates a new cognitive interpretation in the act of "knowing" based on meaning representation caused by relation $\mathrm{R}_{2}$.

Thus the Cartesian split between the subject and the object as well as the mind and the body disappears. Dualistic, dichotomous, thinking is discarded and overlaps among categories are accepted. Consequently, " $\mathrm{sR}_{1} \mathrm{oR}_{2} \mathrm{~s}$ " Ontological fuzzy theory terminology moves beyond the restrictions of twovalued set and logic theory and eliminates most of the axioms exhibited in 
Table 3. Instead it rests mainly on the limited set of axioms shown Table 5 which is for t-norm and co-norm based structures. There are naturally further relaxations for pseudo t-norm and co-norm based structures which are not stated here.

Table 5. Main Stream Axioms of General Fuzzy and Logic Theory

\begin{tabular}{|c|c|}
\hline Involution & $\mathrm{c}(\mathrm{c}(\mathrm{A}))=\mathrm{A}$ \\
\hline \multirow[t]{2}{*}{ Commutativity } & $\mathrm{A} \cup \mathrm{B}=\mathrm{B} \cup \mathrm{A}$ \\
\hline & $\mathrm{A} \cap \mathrm{B}=\mathrm{B} \cap \mathrm{A}$ \\
\hline \multirow[t]{2}{*}{ Associativity } & $(A \cup B) \cup C=A \cup(B \cup C)$ \\
\hline & $(\mathrm{A} \cap \mathrm{B}) \cap \mathrm{C}=\mathrm{A} \cap(\mathrm{B} \cap \mathrm{C})$ \\
\hline \multirow[t]{2}{*}{ Absorption by $\mathrm{X}$ and $\varnothing$} & $A \cup X=X$ \\
\hline & $\mathrm{A} \cap \phi=\phi$ \\
\hline \multirow[t]{2}{*}{ Identity } & $\mathrm{A} \cup \phi=\mathrm{A}$ \\
\hline & $A \cap X=A$ \\
\hline \multirow[t]{2}{*}{ De Morgan Laws } & $c(A \cap B)=c(A) \cup c(B)$ \\
\hline & $c(A \cup B)=c(A) \cap c(B)$ \\
\hline
\end{tabular}

Briefly, every element belongs to a concept class, say A, to a partial degree, i.e., $\mu_{\mathrm{A}}: \mathrm{X} \rightarrow[0,1], \mu_{\mathrm{A}}(\mathrm{x})=\mathrm{a} \in[0,1], \mathrm{x} \in \mathrm{X}$, where $\mu_{\mathrm{A}}(\mathrm{x})$ is the membership assignment of an element $\mathrm{x} \in \mathrm{X}$ to a concept class $\mathrm{A}$ in a proposition.

Furthermore, the descriptive assignment $\mathrm{D}_{[0,1]}$ is verified or asserted to be true, $\mathrm{T}$, or false, F, i.e., $\mu_{\mathrm{V}}: \mu_{\mathrm{A}} \rightarrow\{\mathrm{T}, \mathrm{F}\}$ absolutely in Descriptive fuzzy set theory, where $\mathrm{V}_{\{\mathrm{T}, \mathrm{F}\}}$, or $\mathrm{V}_{\{0,1\}}$, is the veristic assignment which is the atomic building block of the two-valued logic.

On the other hand, if the descriptive assignment $\mathrm{D}_{\{0,1\}}$ or $\mathrm{D}_{[0,1]}$ is verified or asserted to be partially true, i.e., $\mu_{\mathrm{V}}: \mu_{\mathrm{A}} \rightarrow[\mathrm{T}, \mathrm{F}]$ or $[0,1]$ in Veristic fuzzy set theory i.e., fuzzy set theory of truthood, which needs to be further verified or asserted to be absolutely True, $\mathrm{T}$, or False, F, i.e., $\mu_{\mathrm{V}}:\left[\mu_{\mathrm{V}}: \mu_{\mathrm{A}} \rightarrow[0,1]\right] \rightarrow\{0,1\}$ where $\mathrm{V}_{[0,1]}$ is a partial veristic truth assignment but $\mathrm{V}_{\{0,1\}}^{\prime}$ is a secondary absolute veristic assignment which is once again the atomic building block of the two-valued logic!

On the ontological level, levels i and ii, the acceptance of the descriptive assignments $\mathrm{D}_{[0,1]}$ in Descriptive fuzzy set theory and the graded veristic assignment $\mathrm{V}_{[0,1]}$ in Veristic fuzzy set theory together with veristic assignment of $\mathrm{V}_{\{0,1\}}$ for Descriptive fuzzy set theory and Veristic assignment of $\mathrm{V}_{\{0,1\}}^{\prime}$ for Veristic fuzzy set theory provide us the grounding for the formation of fuzzyvalued "Fuzzy Truth Tables" and in turn the derivation of the combination of 
concepts for any two fuzzy sets A and B, when they are represented by a Type 1 fuzzy sets, to be

$$
\text { “A AND B" }=\left\{\begin{array}{l}
\text { FDCF }(A \text { AND B })=A \cap B \\
F C C F(A \text { AND B }) \\
=(A \cup B) \cap(c(A) \cup B) \cap(A \cup c(B)),
\end{array}\right.
$$

and

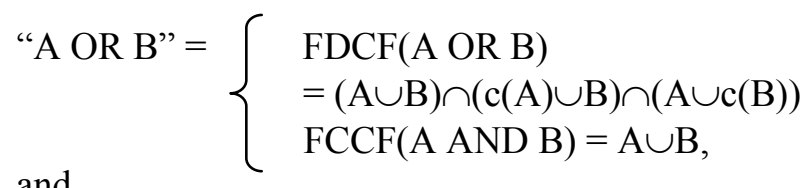

and

$$
\text { “A IMP B" }=\left\{\begin{array}{l}
\text { FDCF }(A \text { IMP B }) \\
=(A \cup B) \cap(c(A) \cup B) \cap(A \cup c(B)) \\
F C C F(A \text { IMP B })=c(A) \cup B,
\end{array}\right.
$$

etc., in analogy to the two-valued set and logic theory where $\operatorname{FDCF}()=.\operatorname{DNF}($. and $\mathrm{FCCF}()=.\mathrm{CNF}($.$) in form only.$

Furthermore, as it is shown $\operatorname{FDCF}(.) \neq \mathrm{FCCF}($.$) and in particular we get$ $\operatorname{FDCF}(.) \subseteq F C C F($.) for certain classes of t-norms and t-conorms. (Türkşen, 1986-2002)

This means that linguistic connectives "AND", "OR", "IMP", etc., are not interpreted in a one-to-one correspondence, isomorphically, to be equal to " $\cap$ ", " $", " c(.) \cup "$, etc. That is the imprecise and varying meanings of linguistic connectives are not precisiated in an absolute manner. Thus in these structures it is assumed that there are no absolute precisiation of the meaning of words nor there are an absolute precisiation of the meaning of connectives. This provides a framework for the representation of uncertainty in the combination of words and connective and hence in reasoning with them.

This particular interpretation and knowledge representation and reasoning forms a unique foundation for Type 2 fuzzy set theory in general and in particular for interval-valued Type 2 fuzzy set theory generated by the combination of linguistic concepts with linguistic connectives even if the initial meaning representation of words are to be reduced to Type 1 membership representation. More general representations start with Type 2 representation schema and then form Type 2 reasoning schemas to capture both imprecision and uncertainty. 
On the General Epistemological Level iii, we have the foundation of the integrated subjectivist-objectivist perspective. Its stance is that real truth is relative and context dependent. It is potentially, partially and approximately accessible and it is to be found on the subject-object integrated interaction. On this level iii, the observation based data are obtained from subject-object interaction with perceptions as well as measurements. That is both human as well as electro mechanical sensors provide data.

Thus representations of objects are developed on perceptions of humans and measurements of sensors for the use of human decision makers. This is done with the assumption of the fact that perception and measurement based models are developed to stand on the foundation proposed on the Ontological level, i.e., $\mathrm{sR}_{1} \mathrm{OR}_{2} \mathrm{~s}$ paradigm.

They are consequently descriptive representations of model concepts on fuzzy(infinite)-valued i.e., $\mathrm{D}_{[0,1]}$ which are verified with the two-valued logic theory, as $\mathrm{V}_{\{0,1\}}$ for the Descriptive fuzzy set theory.

On the other hand, descriptive propositions whether they be $\mathrm{D}_{\{0,1\}}$ or $\mathrm{D}_{[0,1]}$ if they are verified with fuzzy(infinite)-valued truthoods, as $\mathrm{V}_{[0,1]}$ and then they are verified with the two-valued logic theory as $\mathrm{V}_{\{0,1\}}^{\prime}$ then we have a Veristic fuzzy set theory.

Next on the level iv, the correspondence theory of truth "is basically based on fuzzy valued sets, whether they be for Descriptive fuzzy sets, $\mathrm{D}_{[0,1]}$, or Veristic fuzzy sets, $\mathrm{V}_{[0,1]}$, paradigms and two-valued truth (verification) paradigm with either $\mathrm{V}_{\{0,1\}}$ for Descriptive fuzzy set paradigm or $\mathrm{V}_{\{0,1\}}$ for Veristic fuzzy set paradigm which are accepted on the Ontological Level. This means that models developed on the General Epistemological level are to be accepted as true (but approximate) depictions of a real system behaviour. Furthermore, test data are to be used to validate results obtained from the models build on the level iii. Thus results are assumed to computationally but approximately determined as acceptable outcomes for given inputs of the test data,

Therefore on the General Epistemological level, we first have a model expressed in particular as Interval-valued Type 2 form as:

$$
\text { A IMP B }=\left\{\begin{array}{c}
\text { FDCF(A IMP B }) \\
\text { FCCF(A IMP B })
\end{array}\right.
$$


as a descriptive model, an interval-valued Type 2 fuzzy rule, a premise. That is

$\left\{\left\{\mathrm{D}_{[0,1]} \mathrm{V}_{\{0,1\}}\right\}\right.$ IMP $\left.\left\{\mathrm{D}_{[0,1]} \mathrm{V}_{\{0,1\}}\right\}\right\}=\left\{\mathrm{D}_{[0,1]} \mathrm{V}_{\{0,1\}}\right\}$ which is verified as $\mathrm{V}_{\{0,1\}}$ within the framework of a fuzzy inference schema such as Generalized Modus Ponens, GMP, originally proposed by Zadeh as Compositional Rule of Inference, CRI, such that the resultant premise $\left\{\mathrm{D}_{[0,1]} \mathrm{V}_{\{0,1\}}\right\}$ for "A IMP B" combined with a second premise $\left\{\mathrm{D}_{[0,1]} \mathrm{V}_{\{0,1\}}\right\}$ for " $\mathrm{A}$ " result in a consequence $\left\{\mathrm{D}_{[0,1]} \mathrm{V}_{\{0,1\}}\right\}$ for $\mathrm{B}^{*}$, where the fuzzy similarity of $\mathrm{A}^{\prime}$ to $\mathrm{A}$ together with the tnorm and co-norm that is chosen result in $\mathrm{B}^{*}$. The validation is based on a fuzzy comparison of the actual output for a given test input data and model output for the same test input data. The error is usually accepted to be a true, $\mathrm{V}_{\{0,1\}}$, verification but based on a risk statistically but fuzzily evaluated assessment dependent on a fuzzy test of hypothesis and fuzzy accuracy and power of prediction. It should be noted that all of the proceeding exposition which is made for the Descriptive fuzzy set paradigm. A similar exposition is applicable to for the Veristic fuzzy set paradigm as we have explained earlier!

On the Domain-Specific Epistemological Level, we find various developments of system models with applications of technologies known as fuzzy statistical methods, such as fuzzy multi-variate regression equations, fuzzy linear and non-linear optimization algorithms, or fuzzy optimal control schemas developed on subjective-objective data that are obtained by expertise and measurement which are depend on description and validation frameworks that are given as $\left\{\mathrm{D}_{[0,1]} \mathrm{V}_{\{0,1\}}\right\}$.

As well, the validation of the Domain-Specific models are assessed with domain-specific test data that are assumed to be standing on descriptive and verified framework $\left\{\mathrm{D}_{[0,1]} \mathrm{V}_{\{0,1\}}\right\}$. The validations of the domain-specific models are executed with fuzzy inference schemas such as Generalized Modus Ponens as indicated above. They may entail re-computations of, say, fuzzy regression, or fuzzy programming, or fuzzy control models with, test data. Results obtained from such models are assumed to be on $\mathrm{D}_{[0,1]} \mathrm{V}_{\{0,1\}}$ framework for descriptive fuzzy set models based on some level of risk and on $\mathrm{V}_{[0,1]} \mathrm{V}^{\prime}{ }_{\{0,1\}}$ framework for veristic fuzzy logic models.

On Level vii of the proposed hierarch, Application Level proper, we are all quite aware of the vast contributions made to fuzzy sets and systems field by Lotfi A. Zadeh as a foundation for numerous applications. The details of his numerous seminal ideas are well beyond the scope of this sketch. A synopsis of his contributions is briefly summarized in my Plenary talk given at IFSA-2001 World Congress (Türkșen, 2001). Let it suffice to point out here that his consistent emphasis on the foundations of fuzzy set and logic theories have 
provided a grounding for the Application Level vii includes linguistic variables, their representation with fuzzy sets i.e., their precisiation with membership functions, and reasoning with imprecise linguistic terms of linguistic variables that are precisiated with membership functions. This emphasis in turn has led to the notions of Computing With Words, CWW, and more recently Computing With Perceptions, CWP.

It is in these respects that many of the familiar revisions and alternatives to classical thinking, suggested by Black, Lucasiewicz, Kleene, etc., were preliminary break away strategies from the classical paradigm. With the grand paradigm shift caused by Zadeh's seminal work and continuous stream of visionary proposals, it is now clear that most of them reflect very different stances adopted at the more fundamental levels of our proposed hierarchy. Those changes, it appears, have sometimes been made only in a more tacit and implicit manner. In my studies, it became obvious that the most radical revisions are likely to be the ones that stem from modification to be made at the low levels of the proposed hierarchy.

It is in this sense that I had investigated measurement theoretic foundations of membership functions and provided experimental existence of Type 2 fuzzy sets in membership acquisition experiments. Also with this conviction I raised the concern for the Conjunctive and Disjunctive Normal (Canonical) Form representations in the combination of concepts. In turn, it became to the forefront that linguistic connectives "AND". "OR", "IMP", etc., are also imprecise and that they need to be precisiated in a graded manner and thus "AND" does not correspond to t-norm and "OR" does not correspond to a t-co-norm in a one-to-one isomorphic correspondence.

Therefore, each combination of concepts has its own Conjunctive Normal (Canonical) Form that is, for subclasses of t-norms and t-co-norms that are isomorphic to Archimedean norms which are nilpotent or strict, and special cases of (Max-Min) and some ordinal sums, larger in the set sense and greater in the membership sense or equal to its Disjunctive Normal (canonical) Form. This, on the one hand, increases the uncertainty but, on the other hand, exposes risk associated with the indefiniteness in the combinations of imprecise concepts in knowledge representation and reasoning in an approximate manner.

Overall, it appears that these philosophical issues leave Classical thinkers as well as Type 1 fuzzy thinkers with significant dilemmas. Much of the classical work may be seen as an example of a theory that was very heavily committed to sRo model of Cartesian dualism. If one adopts that position on Ontological Level ii, however, one is then left at the General Epistemological Level iii to choose between two responses to the crucial scientific question: 
"From where does truth come?" One must ascribe the origin of truth or valid knowledge to either the "object side" or the "subject side" of the sRo scenario with the former position being known as "objectivism" an the latter "subjectivism".

With the insight-gained over the last $36+$ years of debate, one can say that classical thinkers are confronted with a dilemma: because their sympathies are clearly with the "objectivism" side of the epistemological debate, for the electromechanical systems. On the other hand, the subject matter rests more precisely on the "subjectivity" side in all its richness for the human decisionmaking systems. Thus for the objectivism, it is no wonder that their mechanistic meta-physical explanations demand revisions. Nor is it surprising that their critical writing have quite a different tone as well and perhaps even a different implicit epistemological leanings.

For all these reasons and more, we have proposed that at the very foundation of the Ontological level we need to consider the " $\mathrm{sR}_{1} \mathrm{OR}_{2} \mathrm{~s}$ " paradigm to push to the surface the integrated subjective-objective stand that is exposed by most fuzzy set and logic theory researchers,

\section{GENERAL EPISTEMOLOGICAL CONCERNS}

Beyond the comparison of the classical and fuzzy theory which is discussed in Section 2 above, we now turn our attention to a more fundamental and general epistemological concerns in order to restructure the epistemological foundations for the fuzzy theory. In this section, we will touch upon two major concerns, namely, "explication" and "ratification".

Under these headings there are other issues of epistemological concerns such as:

(i) foundationalism,

(ii) coherentism,

(iii) reliabilism,

(iv) critical rationalism.

Amongst these, we will review the issues of foundationalism and coherentism.

Basically, the concern for "explication" of criteria of evidence or justification asks "What accounts as good, strong, and supportive evidence for belief?" 
Whereas the concern for "ratification" (verification, validation) asks "What is the connection between beliefs being well-supported by good evidence, and the likelihood that it is true?"

\subsection{Foundationalism}

Foundationalism admits many and various variations. One dimension of these variations concerns the material character of the beliefs and claim them to be basic. Fundamental distinctions between those foundationalists are those which take the basic belief to be empirical, and those which take them to be non-empirical.

Within the classical perspective, two basic categories of beliefs are identified as:

(i) Some basic beliefs are justified independently of the support of other beliefs and they are non-empirical in character.

(ii) Some basic beliefs are justified not by the support of other beliefs, but by subject experience, i.e., they are empirical.

These basic beliefs may be derived or not derived whether they are empirical or non-empirical.

For the reconstruction of epistemology in fuzzy theory, we introduce fuzzy degrees to capture imprecision and uncertainty associated with beliefs.

For this purpose, we state the following:

(i)' Some basic beliefs are justified, not by the support of other beliefs, but because of causal or law-like connection between a subjects' belief and the state of affairs which makes it appear true. (i.e., expert knowledge which are considered crisp in the classical perspective but which are intrinsically fuzzy under our $\mathrm{sR}_{1} \mathrm{oR}_{2} \mathrm{~s}$ structure proposed at the ontological level)

(ii)' Some basic beliefs are justified, not by the support of other beliefs; but by virtue of their content, their intrinsically self-justifying character. Again they may be assumed to be crisp or fuzzy depending on the agenda we work on.

(iii)' Some basic beliefs decisively, conclusively, and completely are justified independent of the support of any other belief. This requires the determination of critical, affective variables and the belief that they are 
independent. Clearly the determination of these independent, critical and affective variables requires crisp or fuzzy statistical criteria for selection.

In this regard, we now re-state fuzzy beliefs as follows:

(i)" Some basic beliefs are justified to some fuzzy degree interacting with other beliefs.

(ii)" Some justified beliefs are derived and are justified to some fuzzy degree via direct or indirect support of basic beliefs that are inherently fuzzy.

(iii)" Some justified beliefs are derived at least in part via direct or indirect support of basic beliefs that are inherently fuzzy.

\subsection{Coherentism}

Naturally, a belief is justified if it belongs to a coherent set of beliefs, Such coherent set of beliefs may be categorized as: (i) uncompromizing, (ii) moderated with a weighting, and (iii) moderated with a fuzzy degree. Thus, we state:

(i) Uncompromising Coherentism

A belief is justified iff it belongs to a coherent set of beliefs where no belief within a coherent set has a distinguishing epistemic status and place.

(ii) Moderated Weighted Coherentism

Some beliefs are justified if they belong to a coherent set and they have a distinguishing initial status and justification dependent on a weighted mutual support.

(iii) Moderated Fuzzy Coherentism

Some beliefs are justified if they belong to a coherent set and they have a distinguished initial status and justification by being embedded to a fuzzy degree within a coherent set.

\section{BELIEFS ON FUZZY SETS}

In reconstruction of epistemological concern with a perspective of the fuzzy theory, we next establish the necessary link between beliefs and fuzzy 
theory in order to provide a starting point for further research on "explication" and "ratification" concerns of epistemology under the headings of "foundationalisms" and "coherentism".

\subsection{Beliefs on Type 1 Fuzzy Sets}

In order to determine a belief over Type 1 fuzzy set A, we first express it in terms of its $\alpha$-cuts and $\alpha$-level sets as:

$$
\begin{aligned}
\operatorname{Bel}\left(\mathrm{A}_{1} \mathrm{OR} \mathrm{A}_{2}\right)=\operatorname{Bel}\left(\mathrm{A}_{1} \cup \mathrm{A}_{2}\right) \\
=\operatorname{Bel}(\mathrm{A}) \\
=\sum_{\alpha} \operatorname{Bel}\left(\alpha\left(\mathrm{A}(\mathrm{x})_{\alpha}\right)\right) \\
=\sum_{\alpha}^{\alpha} \alpha \operatorname{Bel}\left(\mathrm{A}(\mathrm{x})_{\alpha}\right)
\end{aligned}
$$

(note that $\Sigma=\cup$, i.e., it is set aggregation and $\alpha$ is a scalar)

Furthermore if we have three $\alpha$-cuts as $\alpha_{1}, \alpha_{2}$, and $\alpha_{3}$ then we write:

$$
\begin{aligned}
& \operatorname{Bel}\left(\mathrm{A}_{1} \mathrm{OR}_{2}\right)=\operatorname{Bel}\left(\mathrm{A}_{1} \cup \mathrm{A}_{2}\right)=\operatorname{Bel}(\mathrm{A}) \\
& \begin{aligned}
\operatorname{Bel}(\mathrm{A}) \quad=\sum_{\alpha} \operatorname{Bel}\left(\alpha\left(\mathrm{A}(\mathrm{x})_{\alpha}\right)\right) \\
=\sum_{\alpha} \alpha \operatorname{Bel}\left(\mathrm{A}(\mathrm{x})_{\alpha}\right)
\end{aligned} \\
& \operatorname{Bel}(\mathrm{A})_{\alpha_{3}, \alpha_{2}, \alpha_{3}} \\
& =\alpha_{1} \operatorname{Bel}\left(\mathrm{A}(\mathrm{x})_{\alpha_{1}}\right)+\alpha_{2} \operatorname{Bel}\left(\mathrm{A}(\mathrm{x})_{\alpha_{2}}\right)+\alpha_{3} \operatorname{Bel}\left(\mathrm{A}(\mathrm{x})_{\alpha_{3}}\right) \\
& -\left(\alpha_{1} \Delta \alpha_{2}\right) \operatorname{Bel}\left(\mathrm{A}(\mathrm{x})_{\alpha_{1}} \cap \mathrm{A}(\mathrm{x})_{\alpha_{2}}\right) \\
& -\left(\alpha_{1} \Delta \alpha_{3}\right) \operatorname{Bel}\left(\mathrm{A}(\mathrm{x})_{\alpha_{1}} \cap \mathrm{A}(\mathrm{x})_{\alpha_{3}}\right) \\
& -\left(\alpha_{2} \Delta \alpha_{3}\right) \operatorname{Bel}\left(\mathrm{A}(\mathrm{x})_{\alpha_{2}} \cap \mathrm{A}(\mathrm{x})_{\alpha_{3}}\right) \\
& +\left(\alpha_{1} \Delta \alpha_{2} \Delta \alpha_{3}\right) \operatorname{Bel}\left(\mathrm{A}(\mathrm{x})_{\alpha_{1}} \cap \mathrm{A}(\mathrm{x})_{\alpha_{2}} \cap \mathrm{A}(\mathrm{x})_{\alpha_{3}}\right)
\end{aligned}
$$

where $\Delta$ is a t-norm. 


\subsection{Belief on Interval-valued Type 2 Fuzzy Sets}

In our interval-valued Type 2 theory, which recently is shown to correspond to a restricted and modified multi-valued mapping of Dempster, which we call "T-formalism"(Türkşen, 2001, 2002), the membership values of the meta-linguistic combination of

" $\mathrm{A}_{1} \mathrm{OR} \mathrm{A}_{2}=\mathrm{A}$ " are mapped into:

(1) the upper bound set approximation

$$
\mathrm{FCCF}(\mathrm{A})=\mathrm{A}_{1} \cup \mathrm{A}_{2}=\mathrm{A} U
$$

(2) the lower bound set approximation

$$
\operatorname{FDCF}(\mathrm{A})=\left(\mathrm{A}_{1} \cap \mathrm{A}_{2}\right) \cup\left(\mathrm{c}\left(\mathrm{A}_{1}\right) \cap \mathrm{A}_{2}\right) \cup\left(\mathrm{A}_{1} \cap \mathrm{c}\left(\mathrm{A}_{2}\right)\right)=\mathrm{A}_{\mathrm{L}}
$$

In turn with the $\alpha$-cut expressions, we obtain:

$$
\begin{aligned}
& \operatorname{Bel}[\mathrm{A}(\mathrm{x})]_{\alpha}=\sum_{\alpha} \alpha \operatorname{Bel}\left[\operatorname{FDCF}(\mathrm{A}(\mathrm{x}))_{\alpha}\right] \\
& \operatorname{Bel}[\mathrm{A}(\mathrm{x})]_{\alpha} \sum_{\alpha} \alpha \operatorname{Bel}\left[\operatorname{FCCF}(\mathrm{A}(\mathrm{x}))_{\alpha}\right]
\end{aligned}
$$

\section{CONCLUSION}

In this paper, we have presented a methodology for the philosophical grounding of fuzzy theory with a particular emphasis on the ontological and epistemological concerns. First a comparison of the classical and fuzzy theory has been discussed. Secondly deeper epistemological concerns of "explication" and "ratification" were restated under the headings of "foundationalism" and "coherentism". Thirdly, issues of basic, drived, empirical beliefs have been extended to include fuzzy beliefs.

Finally, a brief analytical expression of belief is given over Type 1 and interval valued Type 2 fuzzy sets. 


\section{REFERENCES}

Bilgic, T. (1995), Measurement-Theoretic Frameworks for Fuzzy Set Theory with Applications to Preference Modeling, (Ph.D Thesis), University of Toronto, (supervisor, I.B. Türkşen).

Dempster, A.P. (1967), "Upper and Lower Probabilities Induced by a Multivalued Mapping", Annals of Mathematical Statistics, 38, 325-39.

Khun, T. (1962), The Structure of Scientific Revaluations, Chicago: University of Chicago Press.

Pawlak, Z. (1982), "Rough Sets", International Journal of Computer and Information Sciences, 11, 341-56.

Pawlak, Z. (1991), “Rough Sets”, Netherlands: Kluwer.

Resconi, G. and I.B. Türkşen (2001), "Canonical Forms of Fuzzy Truthoods by MetaTheory Based Upon Modal Logic”, Information Sciences, 131, 157-94.

Shafer, G. (1976), Mathematical Theory of Evidence, Princeton: Princeton University Press.

Türkşen, I.B. (1986), "Interval-Valued Fuzzy Sets based on Normal Forms", FSS, $191-210$

Türkşen, I.B. (1994), "Interval-Valued Fuzzy Sets and Compensatory AND", FSS, $87-100$.

Türkşen, I.B. (1996), "Non-Specificity and Interval-Valued Fuzzy Sets", FSS, 80, $87-100$.

Türkşen, I.B. (1999), "Theories of Set and Logic with Crisp or Fuzzy Information Granules", Journal of Advanced Computational Intelligence, 3, 4, $264-73$.

Türkşen, I.B. (1999), "Type I and Type II Fuzzy System Modeling", FSS, 106, 11-34.

Türkşen, I.B. (2001), "Computing with Descriptive and Veristic Words: Knowledge Representation and Reasoning", P.P. Wang(ed.), Computing With Words, (Chapter 10), New York: Wiley 297-328.

Türkşen, I.B. (2002), "Belief, Plausibility and Probability Measures over Type 2 Fuzzy Sets", International Journal of Applied Mathematics and Computer Science, (to appear).

Türkşen, I.B. (2002), "Type 2 Representation and Reasoning for CWW", FSS, 127, 17-36. 
Türkşen, I.B. (2002), "Interval-valued Type 2 Fuzzy Sets, Multi-valued Maps and Rough Sets", (in) A Grmela and N.E.Mastorakis (eds.), Advances in Intelligent Systems, Fuzzy Sets, Evolutionary Computation, WSEAS, 142-46.

Türkşen, I.B. (2002), "Upper and Lower Set Formulas: A Modification of DempsterPawlak Formalism", Special Issue of the International Journal of Applied Mathematics and Computer Science, (submitted).

Zadeh, L.A. (1965), "Fuzzy Sets", Info. Control, 81, 338-53.

Zadeh, L.A. (1996), "Fuzzy Logic: Computing With Words", IEEE-Tran. on FS, 2, 103-11.

Zadeh, L.A. (1999), "From Computing with Numbers to Computing With Words From Manipulation of Measurements to Manipulation of Perceptions", IEEE, Tran. on Circuits and Systems, 45, 105-19.

Zimmerman, H.J. and P. Zysno (1980), "Latent Connectives in Human Decision Making", FSS, 4, 37-51. 